\title{
Actualización en el tratamiento del paciente infectado por el virus de la inmunodeficiencia humana (VIH). 2002
}

\author{
F. Ledesma Martín-Pintado, J. del Romero Guerrero*, J. Locutura Rupérez**, \\ J. A. Vargas NúÑez***, C. Plaza Nohales***** \\ Unidad Docente M FyC Área 6. Centro de Salud Cerro del Aire. Majadahonda. Madrid. \\ Fundación FIT (Formación e Información sobre Tratamientos VIH). *Centro Sanitario \\ Sandoval. Servicio Madrileño de Salud. Comunidad de Madrid. Fundación FIT (Forma - \\ ción e Información sobre Tratamientos VIH). **Servicio de Medicina Interna. Hospital \\ General Yagüe. Burgos. ***Servicio de Medicina Interna I. Hospital Universitario Clínica \\ Puerta de Hierro. Madrid. ****Centro de Salud Cerro del Aire. Majadahonda. Madrid
}

\section{RESUMEN}

Hace 20 años que comenzó la pandemia produ cida por el el virus de la inmunodeficiencia huma na (VIH). Dado el impacto social y económico de la infección y su intensa extensión en los países in dustrializados, se ha producido un desarrollo de conocimiento científico sin precedentes. No obs tante, con los tratamientos actuales sabemos que no es posible erradicar el virus, aunque gracias a ellos las infecciones oportunistas casi han desapa recido y la calidad de vida ha mejorado considera blemente. Esta mejoría evidenciada con terapia combinada antirretroviral, el coste de los medi camentos y-ante todo-los importantes efectos adversos de la medicación, han motivado que cada vez se recomiende comenzar más tarde el tratamiento.

Asumiendo que es preciso seguir a los pacientes asintomáticos durante años antes de comenzar con el tratamiento antirretroviral, si gran parte de los enfermos ya en tratamiento sólo precisan controles periódicos, ajustes de terapia y revisión de interacciones y efectos adversos, ¿podríamos plantear que dicho seguimiento se realizara fuera de los nú cleos hospitalarios?

Palabras clave: VIH. SIDA. Tratamiento anti rretroviral de gran actividad (HAART). Artículo de revisión. Atención Primaria.
The treatment update from the human immunodeficiency virus (HIV) infected patients. 2002

\section{ABSTRACT}

It has been 20 years now since HIV epidemic started. Due to the infection's social and economi cal impact and it's wide spread in the developed countries, a huge scientific knowledge has taken place. Nevertheless with the actual treatments, we know that is impossible to destroy the virus, though they have contributed to almost eradicate the op portunistic infections and the quality of life level has increased tremendously.

This improvements showed by combining antire troviral therapy, drugs cost -and the most impor tant- the negative consequences from the treatment itself, have motivated to start the medication as late as possible.

If we have to follow up the evolution of a patient without symptoms along the years and if a large number of patients in treatment, just only need pe riodical controls, to fit or to modify the treatment, could we then conclude that it would be possible to treat the patients in their natural environment out of hospital?

Key words: HIV. AIDS. Hightly Active Antiretro viral Therapy (HAART). Review literature. Pri mary Health Care.

Aceptación: 08-01-02 


\section{VEINTE AÑOS DE VIH}

Desde que en junio de 1981 fueron comunicados cinco casos de neumonía por Pneumocystis carinii en varones homosexuales en Los Ángeles ${ }^{1}$, hasta la actualidad, la infección por VIH ha representando el mayor despliegue científico en el menor periodo de tiempo de la historia del ser humano. Sólo dos años después de la detección del primer caso, el 20 de mayo de 1983 se aisló un retrovirus - procedente de pacientes con SIDA- parecido a los del tipo HTLV ${ }^{2}$. En marzo de 1985 la FDA americana (Food and Drug Administration) autorizó la comercialización del primer test de detección del VIH. En 1986 los CDC (Centers for Disease Control) publicaron la primera clasificación clínica y analítica de la enfermedad con finalidad práctica ${ }^{3}$ que ya se había quedado obsoleta en diciembre de $1992^{4}$.

Desde los primeros tiempos se planteó el uso de diferentes compuestos antirretrovirales para combatir la infección por virus de la inmunodeficiencia humana (VIH). Fue a lo largo de un ensayo clínico doble ciego cuando se evidenció, incluso antes de finalizarlo, la superioridad de la azidotimidina (AZT o zidovudina) frente al placebo en la mejoría de los pacientes con enfermedad VIH avanzada e inmunodepresión marcada ${ }^{5}$. Éste fue el punto de partida del tratamiento frente al VIH. Posteriores estudios demostraron que el inicio con AZT en fases iniciales de la enfermedad no aportaba excesivas ventajas sobre el comienzo más retrasado. Además la terapia doble ofrecía una respuesta clínica mejor y más duradera ${ }^{6,7}$.

En agosto de 1995 la FDA aprobó para su comercialización el primer miembro de una nueva familia de antirretrovirales: los inhibidores de la proteasa. Con ello comenzó la triple terapia, o terapia antirretroviral de gran actividad, TARGA o HAART (hightly active antiretroviral therapy). La mejoría de los pacientes fue espectacular. El número de ingresos hospitalarios asociado a infecciones oportunistas disminuyó drásticamente. La calidad de vida de los pacientes correctamente tratados se equiparó al de otras enfermedades crónicas $^{8-20}$. Se replanteó la posibilidad de suspender determinadas quimioprofilaxis dado que la situación inmunitaria se mostraba controlada. Incluso se llegó a considerar la posibilidad de llegar a erradicar el virus.

La aparición de toxicidad y efectos adversos en algunos pacientes y la gran mutabilidad del virus, con una continua aparición de resistencias, promovieron el desarrollo de nuevos fármacos. Así apareció en junio de 1998 el primer inhibidor de la transcriptasa inversa no análogo de nucleósidos que venía a aportar una nueva alternativa en triple terapia con menos comprimidos y diferente perfil de resistencias.

En el momento en que los tests de resistencias están a la orden del día para la elección personalizada de la terapia TARGA, esperamos la próxima comercialización de dos nuevos grupos de fármacos para completar el arsenal antirretroviral: los análogos de nucleótidos y los inhibidores de la fusión. Entre los primeros, el tenofovir inhibirá la transcriptasa inversa posiblemente sin problemas de toxicidad mitocondrial, con mayor fortaleza frente a las resistencias y todo ello mediante un único comprimido al día. El T-20 podría ser el primer inhibidor de la entrada del VIH a las células comercializado aportando así una nueva diana de acción frente al VIH, con efecto sinérgico en la actividad de los tratamientos hasta ahora disponibles pero sin sumar toxicidad (Tabla I).

El gran desarrollo terapéutico conseguido ha sido posible gracias a la investigación de las empresas farmacéuticas, a la continua realización de ensayos clínicos, al esfuerzo de enfermos y personal sanitario y al apoyo de las instituciones sanitarias.

Este gran despliegue de medios a lo largo de dos décadas lleva promoviendo un continuo flujo de información con marcadas peculiaridades. Así, por ejemplo, los medicamentos se han ido aprobando de forma acelerada, con ensayos clínicos de -inclusosólo 16 semanas de duración (cuando lo habitual era al menos 48 semanas) y muchas veces con un diseño cuyo objetivo era la rápida constatación de su eficacia clínica para conseguir su inmediata comercialización. Una vez disponibles, se realizaban ya ensayos fase IV en los que aparecen siempre nuevos datos sobre eficacia, toxicidad, interacciones, etc. Es en esta situación de continuo aporte de datos en la que nos encontramos, con gran parte de los enfermos incluidos dentro de algún protocolo clínico, y en la que casi a diario surgen novedades de mayor o menor importancia. De esta manera, la publicación final de los datos en una revista de prestigio (meses-años más tarde) queda a veces en un segundo plano, cobrando gran interés las comunicaciones en congresos y las publicaciones vertidas directamente en internet por instituciones oficiales (IAS) y congresos (CROI, ICAAC). La suscripción a las listas de distribución de estos organismos (CDC, FDA, Centros Epidemiológicos Europeos, diversas universidades, etc.) mediante el correo electrónico se convierte así en un arma de necesidad para mantenerse al día y que está sustituyendo a la comunicación científica en el formato tradicional.

Para regularizar y ajustar las indicaciones terapéuticas a los continuos flujos de información, diversas asociaciones de distintos países han promovido la confección de guías de manejo terapéutico ${ }^{22-26}$ algunas de las cuales se actualizan cada pocos meses. En ellas se reflejan diferentes niveles de recomendación, dependiendo de si se trata de estudios aleatorizados y controlados (nivel A), estudios de caso-control o de cohortes (nivel B) y estudios descriptivos o recomendaciones de grupos de expertos (nivel C). Si bien la guía más co- 


\section{ANTIRRETROVIRALES}

Inhibidores de la transcriptasa inversa

Análogos de nucleósidos

$\begin{array}{ll}\text { Zidovudina (ZDV, AZT)* } & 1 \text { caps/ } 12 \mathrm{~h} \\ \text { Didanosina (ddl)*** } & 1 \text { caps/ } 24 \mathrm{~h} \\ \text { Zalcitabina (ddC)* } & 1 \text { comp/ } 8 \mathrm{~h} \\ \text { Estavudina (d4T)* } & 1 \text { comp/ } 12 \mathrm{~h} \\ \text { Lamivudina (3TC)* } & 1 \text { comp/ } 12 \mathrm{~h} \\ \text { Abacavir (ABC)* } & 1 \text { comp/ } 12 \mathrm{~h} \\ \text { Zidovudina/ lamivudina } & 1 \text { comp/ } 12 \mathrm{~h} \\ \text { Zidovudina/ lamivudina/ abacavir } & 1 \text { comp/ } 12 \mathrm{~h} \\ \text { Emtricitabina (FTC) } \varnothing & \end{array}$

DAPD $\varnothing$

ACH $126,443 \varnothing$

dOTC $\varnothing$

No análogos de nucleósidos

Efavirenz*
Nevirapina*

¿Capravirina?

Calanolida $A \varnothing$

Emivirina $\varnothing$

TMC $120 \varnothing$

TMC $125 \varnothing$

DPC $083 \varnothing$

DPC $961 \varnothing$

Análogos de nucleótidos

Tenofovir** $\varnothing$
Inhibidores de la Proteasa

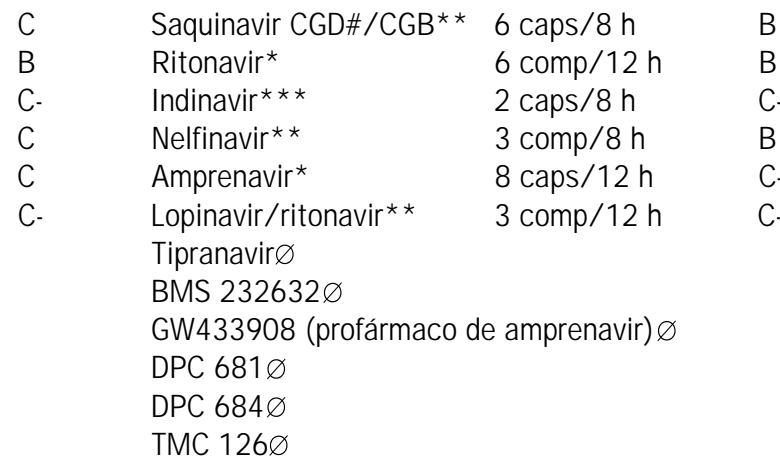

3 caps por la noche C$1 \mathrm{comp} / 12 \mathrm{~h}(1) \quad \mathrm{C}$

Inhibidores de la Fusión o entrada

T-20 (Pentfusida) $\varnothing \quad$ SC/ $12 \mathrm{~h}$
T-1249 $\varnothing$
PRO $542 \varnothing$
PRO $367 \varnothing$
S $1360 \varnothing$

$1 \mathrm{comp} / 24 \mathrm{~h}$

* Puede tomarse con o sin alimentos

** Ha de tomarse junto a alimentos

*** Ha de tomarse en ayunas (al menos 2 horas)

\#Sólo está aprobada su administración junto a ritonavir

$\varnothing$ En estudio precomercialización

B,C: Clasificación FDA de Seguridad en embarazo ${ }^{21}$ : B estudios en animales no han consiguido demostrar daño fetal, pero no se han realizado estudios en humanos. C: Sin resultados claros en animales ni estudios en humanos. Valorar riesgo/ beneficio.

- Antirretroviles menos indicados en embarazo por teratogenicidad en animales en ensayos o por escasa información disponible (aunque sean catalogados como "C" por la (FDA).

(1) Precisa escalonar las dosis de inicio: 1 comp/ $24 \mathrm{~h}$ durante los primeros 15 días

Nota: Las dosis indicadas pueden sufrir variaciones, en especial las de inhibidores de proteasa si se pauta en combinación con ritonavir.

nocida es la del Departamento de Salud y Servicio Humanos de Estados Unidos y la Fundación Henry Kaiser $^{26}$, las británicas y las francesas han ofrecido tradicionalmente un punto de vista terapéutico relativamente más conservador ${ }^{22,25}$. En nuestro país el Grupo de Estudio del SIDA (GESIDA) y el Plan Nacional del SIDA publicaron durante el año 2000 la última versión conjunta de las recomendaciones españolas, pero no ha sido actualizada desde enton$\operatorname{ces}^{24}$. Asimismo todas estas instituciones editan guías específicas sobre la transmisión vertical, tratamiento en pediatría, profilaxis postexposición, actualización en manejo de infecciones oportunistas, de linfomas, etc. (Tabla II).

\section{ACTUALIZACIÓN EPIDEMIOLÓGICA}

Las cifras de afectados han ido creciendo de una forma vertiginosa a lo largo de los años. En diciembre de 2001 la ONU contabiliza 5 millones de personas infectadas en este año, de los cuales 1,8 millones son mujeres y 800.000 son menores de 15 años. Con ello asciende a 40 millones las personas portadoras del virus en el mundo, la mayoría de las cuales residen en países subsaharianos. En estas áreas el porcentaje de mujeres entre los portadores de la infección supera el $55 \%$, la trasmisión vertical es algo cotidiano y el acceso a medidas diagnósticas, preventivas o terapéuticas realmente escaso. En algunos países de 
Tabla II CONDICIONANTES DEL TRATAMIENTO FRENTE AL VIH

No es posible erradicar la infección por VIH con los tratamientos actualmente disponibles.

Se precisa -al menos- terapia triple para controlar la replicación viral

La alta mutabilidad viral favorece la aparición de resistencias:

El control de la adherencia se muestra un tema prioritario

Es de gran importancia el ajuste de nuevos tratamientos en función de los tests de resistencias Los estudios farmacocinéticos cada día cobran mayor importancia para optimizar las terapias

El alto índice de efectos adversos e interacciones, el coste, el problema de las resistencias y la buena recuperación inmune con el TARGA justifican el demorar lo más posible el inicio del tratamiento antirretroviral (350-200 CD4/ $\left.\mathrm{mm}^{3}\right)$

La frecuente aparición de resistencias y la limitación en el arsenal terapéutico han hecho cambiar la mentalidad terapéutica: se ha pasado del uso puntual de la combinación más potente, al diseño a largo plazo de combinaciones rescatables para tratar de evitar el multifracaso

Para optimizar el tratamiento, disminuir la toxicidad y estimular las defensas se están planteando diversas estrategias como la adición de medicamentos inmunosupresores o inmunoestimulantes y las interrupciones programadas del tratamiento

VIH: virus de la inmunodeficiencia humana TARGA: tratamiento antirretrovial del gran actividad.

África subsahariana la tasa de prevalencia del VIH entre la población general supera el $20 \%$ y se estima que $1 / 3$ de los niños menores de 15 años de esas zonas morirán por esta causa en los próximos años.

Desde el comienzo de la pandemia han fallecido en todo el mundo más de 22 millones de personas.

Mientras que en África viven cerca de 3/4 del total de portadores del VIH, en Europa occidental la prevalencia del VIH entre adultos ronda el $0,3 \%$ (560.000 casos) y en América del norte el 0,6\% ( 940.000 casos). No obstante los estados de la antigua Unión Soviética representan un peligro latente para la expansión de la pandemia dado el preocupante aumento de casos detectados en el pasado $\mathrm{año}^{27}$. En estos últimos países, la drogadicción intravenosa representa una primera gran amenaza, siendo claramente más frecuente la infección entre varones que entre mujeres.

En España se calcula que hubo 2.745 casos nuevos de SIDA a lo largo del año pasado, lo que supone una disminución del $7 \%$ en el número de diagnósticos nuevos respecto al año previo. Sin embargo, el núme- ro de portadores del VIH se mantiene o aumenta, estimándose entre 100.000 y 140.000 casos conocidos vivos en nuestro país en el momento actual ${ }^{28}$. Un $35,7 \%$ de ellos corresponden a diagnósticos tardíos (como consecuencia de una enfermedad definitoria de SIDA ${ }^{29}$. La incidencia de transmisión vertical ha disminuido un $80 \%$ desde $1995^{28}$. La proporción de enfermos de SIDA notificados en nuestro país que son originarios de otros países ha pasado de ser un $2,4 \%$ del total de los casos conocidos entre el año 1981 y el 2000 a representar hasta un $16 \%$ de nuevos diagnósticos de infección por VIH en un reciente estudio español ${ }^{29}$. De acuerdo con estos datos, teniendo en cuenta los fuertes flujos migratorios que se están produciendo en los últimos años y la vulnerabilidad de estas poblaciones, deben ser especialmente potenciadas las actividades de vigilancia epidemiológica y educación sanitaria en minorías étnicas y poblaciones inmigrantes. Desde el inicio de la epidemia se han comunicado 61.028 casos de SIDA en nuestro país, de los cuales más de la mitad ya han fallecido. En su mayoría, la transmisión ha sido debida al uso compartido de material de venopunción para la drogadicción parenteral, aunque la relajación en la prevención, especialmente entre varones homosexuales, representa un riesgo en la actualidad. Así la incidencia de seroconvertores para el VIH entre homosexuales seronegativos que acudían a revisiones periódicas en una clínica de enfermedades de transmisión sexual (ETS) de Madrid ha pasado del 1,06\% en 1995 a $2,16 \%$ en el año $2000^{30}$. Este aumento de la transmisión por VIH se está observando paralelamente a un incremento de las gonococias y sífilis en este colecti$\mathrm{vo}^{30-35}$. Por ello, se sigue perfilando como principal reto el diagnóstico precoz y seguimiento de nuevos casos de seropositividad y la estrecha vigilancia del mantenimiento de las conductas preventivas.

\section{HASTA EL INICIO DEL TRATAMIENTO}

En estos momentos en que el inicio del tratamiento se puede retrasar años tras el diagnóstico de infección por VIH, el médico de Atención Primaria podría desempeñar una función fundamental en el diagnóstico y seguimiento del paciente, su pareja y entorno, en la prevención y/o detección de infecciones, y en la progresiva mentalización y adiestramiento del afectado para afrontar el futuro tratamiento con el máximo conocimiento de sus posibles ventajas, desventajas, limitaciones y complicaciones.

El diagnóstico de infección por VIH se basa en la positividad vertida por el test de ELISA seguida de la confirmación por Western blot. Estaría especialmente indicado descartar la enfermedad en pacientes que refieren haber realizado prácticas sexuales de riesgo, que presenten ETS, con herpes simple recidivante o zóster, candidiasis oral o va- 
ginal recidivante (en ausencia de otros procesos que lo justifiquen), neumonías graves en pacientes jóvenes, tuberculosis activa o latente, y, por supuesto, en el estudio inicial de toda mujer embarazada.

La historia clínica, incluyendo referencia a conductas de riesgo, enfermedades definitorias de SIDA en el pasado, valoración de las parejas sexuales, hábitos tóxicos, etc., ha de completarse con una exploración completa en busca de lesiones cutáneas, orofaríngeas o genitales, adenopatías, masas u organomegalias, alteraciones retinianas, etc. La evolución de la infección por VIH la delimitaremos con los recuentos de linfocitos CD4 y las determinaciones de carga viral plasmática (valor pronóstico) ${ }^{36,37}$. Dichos controles suelen ser realizados cada 3-4 meses en pacientes sin tratamiento, cada 2-8 semanas en los primeros meses de terapia y posteriormente cada 3-4 meses.

En el estudio inicial se incluirán hemograma, orina elemental, bioquímica sanguínea, carga viral y recuento de CD4 y CD8. Es de especial importancia el control serológico de estos pacientes especialmente frente a las hepatitis virales, sífilis, infección por toxoplasma, citomegalovirus y varicela. También se realizará un test de tuberculina inicial (y anual), una revisión ginecológica anual en mujeres (exudado y citología) y la búsqueda de posibles ETS en varones según conductas (exudado anal, uretral, orofaríngeo, etc.).

Con un buen estado inmune, las vacunaciones con preparados sintéticos están indicadas, especialmente frente a hepatitis virales A y B, neumococo, gripe y vacunación de recuerdo frente al tétanos. Algunas de ellas (como las de las hepatitis A y B) podrían precisar el doble de las dosis habituales y realizar controles postvacunales para comprobar la respuesta. En caso de ser ésta insuficiente sería posible repetir la pauta previa. Otras vacunas estarían totalmente contraindicadas, como la BCG, la de la fiebre amarilla o la antitifoidea oral.

Aunque la presente revisión se centra en la infección del adulto, no debe dejar de mencionarse la importancia de las vacunaciones en los niños portadores del VIH. Si bien se deben eludir vacunas de virus vivos como la antipolio oral de Sabin -VPOtanto en el portador de VIH como en todos los contactos próximos, es de gran importancia la vacunación con la vacuna inactivada anti-Polio (VPI), la triple vírica (sarampión, parotiditis, rubéola), la combinada difteria-tétanos-pertussis, la antineumocócica, la conjugada frente al Haemophilus influen zae tipo b, las vacunas frente a las hepatitis A y B, frente al virus de la Influenza (a partir de los 6 meses de edad), frente al meningococo en algunas situaciones, e -incluso- se plantea la posibilidad de utilizar la nueva vacuna frente a la varicela en determinados casos.
Tal vez el médico de familia debería ser el sanitario con mayores posibilidades de entablar un seguimiento próximo al paciente y a su pareja. Desde la Atención Primaria se pueden buscar los recursos necesarios para informar a los afectados, para actuar en el campo de la prevención, preparar al paciente para un posible futuro tratamiento $\mathrm{y}$, en definitiva, para que el enfermo llegue relativamente concienciado para afrontar el TARGA. Un control exclusivamente hospitalario con revisiones espaciadas, con poco tiempo disponible para cada paciente y pudiendo ser atendido en cada visita por un profesional distinto, podría no ofrecer la suficiente información y confianza al afectado y -con toda seguridad-ser insuficiente para que exprese sus dudas y sea convenientemente informado. No obstante, en muchos centros este problema se ha solventado centralizando la atención al paciente VIH en uno o varios facultativos.

\section{CUÁNDO COMENZAR EL TRATAMIENTO}

Atendiendo fundamentalmente al estado inmune del paciente, existe un amplio consenso sobre la necesidad de empezar el tratamiento antes de que exista riesgo de desarrollar infecciones oportunistas o en todo paciente con infección sintomática.

Hasta hace un par de años se promovía el "gol pear fuerte y pronto al virus" con la finalidad de evitar el deterioro de las defensas y para erradicar al VIH. Hoy se ha comprobado que el sistema inmune tiene capacidad para recuperarse aunque iniciemos el TARGA en fases más avanzadas y que -en la práctica- no es posible erradicar el virus.

Se han realizado varios estudios que muestran una aparente mejoría relativa con la terapia durante la primoinfección (en caso de que ésta sea detectada $)^{38,39}$, ya que es posible reducir la replicación viral en plasma, ganglios linfáticos e intestino ${ }^{40,41}$ y -desde un punto de vista inmunológico- la destrucción inmune es menor y la recuperación más rápida y completa. No obstante, este inicio temprano del tratamiento no se recomienda salvo en casos especialmente sintomáticos y en el contexto de ensayos clínicos. La toxicidad a largo plazo, la inevitable aparición de resistencias y los inconvenientes que todo ello representa para el paciente son razones de peso para diferir el tratamiento hasta que éste sea imprescindible. Retrasando la exposición a fármacos retrasaremos el problema de la toxicidad y del cumplimiento y reduciríamos el desarrollo de mutaciones que confieran resistencia.

Lo más frecuente es diagnosticar la infección por VIH durante la infección crónica. Es muy probable que el portador del VIH se encuentre totalmente asintomático. Durante años sus defensas serán suficientemente eficaces y el paciente -sin 
terapia antirretroviral- podrá hacer una vida normal, siempre conociendo el riesgo de transmisión que existe y cómo evitarlo. También es frecuente diagnosticar el VIH en pacientes con enfermedad evolucionada, tal vez durante su primer episodio de enfermedad definitoria de SIDA. En el pasado año, de los diagnósticos nuevos de VIH en España, alrededor del $35 \%$ cumplían ya criterios de SIDA $^{28,29}$. Estas elevadas cifras de diagnóstico tardío tal vez nos deberían hacer reflexionar y motivarnos para reforzar los esfuerzos en el diagnóstico precoz.

El inicio del tratamiento con recuentos de CD4 menores de $200 / \mathrm{mm}^{3}$ conlleva una supervivencia claramente inferior que si la terapia se inicia con cifras mayores (estudio de cohortes) ${ }^{42}$. Si se inicia el tratamiento sobre $350 \mathrm{CD} 4 / \mathrm{mm}^{3}$ la supervivencia podría ser mayor que si se retrasa más la terapia ${ }^{43}$. No obstante, algunos expertos matizan estas conclusiones alegando una dispar contabilización del tiempo total de evolución entre unos y otros.

En cualquier caso, los estudios delimitan una zona de riesgo creciente entre 350 y 200 linfocitos CD4. Es en este intervalo cuando en la actualidad se recomienda iniciar la terapia en el paciente asintomático. Otros aspectos de interés que se deben valorar a la hora de tomar la decisión de inicio antes o después son la caída brusca de CD4 en los últimos meses (factor de riesgo), la evolución de la carga viral y la preparación y predisposición del paciente (Tablas IIIa y IIIb).

La quimioprofilaxis primaria de infecciones oportunistas debe realizarse en caso de que se alcancen dinteles mínimos de CD4. Así por ejemplo se incrementa el riesgo de neumonía por Pneumocystis carinii o de diarrea por Cryptospo ridium parvum con recuentos de CD4 menores de 200 células $/ \mathrm{mm}^{3}$. Con menos de $100 \mathrm{CD} 4 / \mathrm{mm}^{3}$ hay que estar atentos a la esofagitis candidiásica, la encefalitis por toxoplasma, la infección diseminada por Mycobacterium tuberculosis o Myco bacterium avium complex, el herpes simple agresivo, la retinitis por Citomegalovirus, etc. La sospecha de cualquiera de estos procesos requeriría de la valoración hospitalaria por parte del especialista.

Tabla Illa

INICIO DEL TRATAMIENTO EN LA INFECCIÓN CRÓNICA

Guía Asociación Britanica de VIH (BHIVA) Julio 2001. http:// www.bhiva.org/

\begin{tabular}{lll}
\hline \multicolumn{2}{c}{ Síntomas } & Recomendar \\
CD4 & $<200$ & Recomendar \\
& $200-350$ & Considerar \\
$>350$ & Diferir \\
& & Carga viral \\
& & Intención del paciente \\
&
\end{tabular}

Tabla IIIb

INICIO DEL TRATAMIENTO EN LA INFECCIÓN CRÓNICA ASINTOMÁTICA

Guía americana (DHHS. HJ. Kaiser FF). Febrero 2002. www. hivatis.org

\begin{tabular}{|c|c|c|}
\hline$>350$ CD4 & $\begin{array}{l}\text { Carga viral } \\
<30.000^{*} \\
<55.000 * *\end{array}$ & $\begin{array}{l}\text { Diferir } \\
\text { Riesgo de progresión a SIDA } \\
\text { en } 3 \text { años sin tratamiento: }<15 \%\end{array}$ \\
\hline$>350$ CD4 & $\begin{array}{l}\text { Carga viral } \\
>30.000 * \\
>55.000 * *\end{array}$ & $\begin{array}{l}\text { Recomiendan diferir el inicio } \\
\text { Riesgo de progresión a SIDA } \\
\text { en } 3 \text { años sin tratamiento: }>30 \%\end{array}$ \\
\hline $350-200$ CD4 & $\begin{array}{l}\text { Carga viral } \\
\text { cualquier valor }\end{array}$ & $\begin{array}{l}\text { Ofrecer tratamiento: } \\
\text { ¿esperar su inicio y vigilar evolución? }\end{array}$ \\
\hline$<200$ CD4 & \multicolumn{2}{|c|}{$\begin{array}{c}\text { Carga viral } \\
\text { cualquier valor Tratar }\end{array}$} \\
\hline
\end{tabular}

* bDNA (versión 2.0)

**RT-PCR o bDNA (versión 3.0)

Tras la instauración del TARGA algunas de las profilaxis primarias o secundarias podrían ser retiradas una vez conseguido el mantenimiento de la recuperación inmune.

\section{ELECCIÓN DE TERAPIAS COMBINADAS}

Desde el inicio de los tratamientos frente al VIH se ha tratado de ofrecer lo mejor a los pacientes. Hemos buscado el tratamiento más potente; hemos cambiado a nuevas combinaciones; nos hemos inclinado hacia los prometedores medicamentos cuando aparecían. Todo era nuevo: la enfermedad, los fármacos, la evolución de los pacientes. Con el tiempo nos hemos ido encontrando con algunos pacientes multitratados, con un muy difícil rescate que permita mantener estables los CD4 y la carga viral en cifras bajas. Retrospectivamente, y atendiendo a la experiencia adquirida a lo largo de estos veinte años, podríamos considerar que hay dos puntos de máxima prioridad para optimizar nuestras posibilidades terapéuticas. La primera es un uso racional de los antirretrovirales. Ya no interesa "darle fuerte y darle pronto" sino ir secuencialmente. Hoy se recomienda comenzar por triples terapias que, aunque menos potentes que otras, permitan reiterados rescates para garantizar un tratamiento eficaz durante el mayor tiempo posible. (Cuando una terapia TARGA comienza a fallar, los CD4 caen y la carga viral se dispara, se denomina rescate a la capacidad de recuperar la situación con una nueva combinación terapéutica, lo que no siempre es posible debido a las resistencias cruzadas, a la falta de antirretrovirales de reserva, etc.). El segundo aspecto del máximo interés es el fomentar un correcto cumplimiento del tratamiento por parte del paciente. 
La elección de la terapia TARGA debe ser individualizada para cada caso, buscando la posibilidad más cómoda según las características de cada paciente, con una planificación a largo plazo, que seleccione pocos virus resistentes y que consiga una supresión duradera de la carga viral y -consiguientemente- la recuperación inmune. No se han realizado todavía estudios que muestren la superioridad clínica de ninguna combinación TARGA. No obstante, existe mayor experiencia con las triples terapias que contienen un inhibidor de proteasa y dos análogos de nucleósidos que cuando se utiliza un no análogo y dos análogos o con la triple combinación de análogos (Tabla IV).

En el paciente asintomático debe valorarse también la elección de una terapia triple lo más cómoda posible. La cantidad de comprimidos difiere ampliamente dependiendo del fármaco utilizado. Si bien los inhibidores de proteasa se dosifican mediante un mayor número de comprimidos, con ellos se dispone de una mayor experiencia en tratamientos TARGA (ensayos clínicos aleatorizados doble ciego). La acción frente al VIH la ejerceríamos sobre dos dianas (proteasa y la transcriptasa inversa). Otro punto a favor del uso de esta familia es que la resistencia a los inhibidores de proteasa precisa de una cadena de múltiples mutaciones hasta que aparece la resistencia de la cepa viral. Si bien la mayoría de las mutaciones de resistencia son cruzadas (y por ello restan eficacia) a todos los inhibidores de proteasa $^{44,45}$, en terapias iniciales con nelfinavir se podría producir primeramente una disminución de eficacia debida a mutaciones particulares del virus a este fármaco que no interferirían gravemente con otros inhibidores de proteasa. Para optimizar las terapias con inhibidores de proteasa desde el punto de vista farmacocinético y farmacodinámico se

Tabla IV

COMBINACIONES MÁS FRECUENTES DE ANTIRRETROVIRALES

Efavirenz

Nelfinavir

Indinavir

Ritonavir+lopinavir

Ritonavir+saquinavir

Ritonavir+indinavir

Nevirapina

Combinaciones altamente contraindicadas

Estavudina+zidovudina

Zalcitabina+didanosina

Zalcitabina+lamivudina

Zalcitabira+estavudina

Estavudina+didanosina en embarazo*

* Por toxicidad altamente aumentada. Modificado de DHHS, NIH, J Kaiser Family Foundation Guidelines (EE.UU.) puede -posteriormente- asociar ritonavir a otro de ellos (saquinavir, indinavir o lopinavir especialmente $)^{46}$. Dado que ritonavir inhibe el citocromo P450, con su uso a dosis bajas se consiguen alcanzar mayores concentraciones séricas del otro inhibidor de proteasa que se incluya en la combinación y mantenerlas durante mayor tiempo. Esto puede ayudar a optimizar la eficacia de las combinaciones a la vez que se aumentan los intervalos de dosificación ${ }^{47}$. Asimismo, las triples terapias basadas en un inhibidor de proteasa y dos análogos de nucleósidos han mostrado gran eficacia tanto en pacientes adultos ${ }^{10,12,8,9,48-53}$ o niños ${ }^{54,55}$ con enfermedad avanzada y/o multitratados.

Las terapias de inicio basadas en un no análogo de nucleósido (efavirenz o nevirapina) y dos análogos de nucleósidos son claramente más cómodas dado el menor número de dosis y de comprimidos. No obstante existe menos experiencia que con las basadas en inhibidores de proteasa, aunque los últimos resultados son alentadores ${ }^{56-59}$. No se ha realizado ningún estudio aleatorizado que compare directamente eficacia entre terapias con efavirenz y nevirapina. Como principal inconveniente al uso temprano de no análogos estaría la posibilidad de aparición de resistencia. Esta podría ser conferida por una sola mutación, con pérdida de efectividad para ambos componentes de dicho grupo que, por tanto, perderían su eficacia para terapias futuras.

Se está estudiando la utilización de terapias triples con tres análogos de nucleósidos, siendo uno de ellos el abacavir. Los resultados parecen especialmente interesantes en pacientes con carga viral baja $^{60,61}$ aunque hay poca experiencia y su repercusión sobre las resistencias frente a esta familia de antirretrovirales podrían representar un problema. No obstante, esta terapia también ofrecería una mayor comodidad para el paciente debido al menor número de comprimidos que precisa.

\section{Y DESPUÉS VIENE EL CAMBIO DE ANTIRRETROVIRALES}

El tiempo de duración de la supresión viral con la primera pauta es un marcador de gran importancia para el futuro. La respuesta virológica inicial predice la eficacia a largo plazo. Así, la supresión de la carga viral por debajo de 50 copias del ARN del VIH/ml (carga viral sanguínea indetectable) nos hará suponer una respuesta mantenida más larga que cuando la carga viral queda por encima de 400 copias/ml o cuando tarda en constatarse esta caída. El hecho de que la carga viral sea indetectable quiere exclusivamente decir que no se detecta presencia de más de 50 copias de ARN VIH por mililitro de sangre. La replicación sanguínea puede seguir existiendo (aunque en proporciones significativamente menores). Además, 
dentro de sus reservorios (linfocitos, ganglios linfáticos, etc.) el virus sigue presente con una reproducción a menor escala.

Hoy es ampliamente conocida la facilidad del VIH para sufrir inserciones o deleciones en las regiones del genoma del VIH que codifican la trasncriptasa inversa o la proteasa. Con ellas consiguen hacerse más resistentes a los fármacos. Estas mutaciones pueden surgir como reacción a la exposición a un fármaco (primarias) y ello conferiría una desventaja cinética o menor capacidad replicativa. Posteriormente el virus puede experimentar nuevas mutaciones (secundarias) cuya finalidad sea recuperar esa eficiencia biológica perdida. Todas estas mutaciones serían las que conferirían una resisten cia genotípica frente a determinado fármaco. La alta tasa de mutación viral hace que en cada momento un mismo individuo sea portador de entre $10^{5} \mathrm{y}$ $10^{10}$ variantes genéticas distintas del VIH (cuasiespecies). Sólo las poblaciones principales serán detectadas en los tests de resistencias.

No todos los antirretrovirales presentan la misma facilidad para que se desarrollen resistencias frente a ellos. Los denominados de "barrera gené tica baja" que con una mutación pierden eficacia (por ejemplo, 3TC, nevirapina o efavirenz) o los de "barrera genética alta" que precisan un mayor número de mutaciones (por ejemplo, d4T o ddI o los inhibidores de proteasa). Generalmente, el tiempo que tarda en desarrollarse la resistencia es proporcional al número de mutaciones requeridas para ello. Las resistencias fenotípicas aparecen como resultado de las previas y se traducen en la necesidad de alcanzar concentraciones séricas mayores (concentraciones inhibitorias $\mathrm{CI}_{50}, \mathrm{CI}_{90}$ ) para inhibir la replicación del virus ${ }^{62}$.

En la actualidad, en nuestro país, existen enfermos portadores de resistencias incluso antes de comenzar el tratamiento. Un estudio realizado en Madrid ha llegado a la conclusión de que 1/4 de los individuos recientemente infectados por vía sexual han adquirido virus portadores de resistencias. Incluso un $6,7 \%$ de estos mostraban resistencia a múltiples fármacos ${ }^{63}$. Los últimos datos españoles nos sugieren que -entre individuos en tratamiento- cerca del $75 \%$ presentan resistencia a análogos de nucleósidos, cerca de la mitad a los inhibidores de proteasa (especialmente a indinavir) y otro $50 \%$ a los no análogos de nucleósidos $^{64}$. Este es el motivo de que se realicen los tests de resistencias para buscar los fármacos más indicados en cada momento y para cada enfermo. En ningún caso -incluso en pacientes multirresistentes- está indicado suspender el tratamiento ya que el declive inmunitario sería brusco y grave. En estos enfermos en multirrescate, la finalidad es mantener una replicación viral controlada, que sea la menor posible, con objeto de evi- tar la imparable caída de los CD4. Para ello se llegan a utilizar diversos potenciadores farmacocinéticos e inmunológicos, fármacos en estudio y cócteles de antirretrovirales de incluso nueve fármacos ${ }^{65}$. En estas situaciones el estudio genotípico y fenotípico de las resistencias puede ser de gran utilidad para seleccionar una combinación compuesta por los fármacos cuya actividad se vea menos disminuida en cada caso.

Los tests de resistencias podrían ayudarnos a elegir mejor las pautas, a rescatar los tratamientos fallidos con más precisión, modificando el tratamiento en función de las sensibilidades y, en definitiva, a conseguir una terapia óptima para cada paciente. Diversos estudios han respaldado ya su utilidad ${ }^{66-69}$. Los tests genotípicos nos informarían de la presencia de mutaciones puntuales que han sido clasificadas como inductoras de resistencia atendiendo a varios bancos de datos. Los resultados han de ser aplicados a cada fármaco pero sólo en el contexto de la combinación recibida en ese momento. Los tests fenotípicos determinarían la capacidad del virus de un enfermo concreto para crecer ante determinadas concentraciones de antirretrovirales (lo que, por analogía con bacteriología, se denomina $\mathrm{CI}_{50}$ o "concentración inhibitoria ${ }_{50}$ "). Dado que estas pruebas se realizan mediante la amplificación de secuencias, es lógico sospechar que sólo se detectan las variantes predominantes. Además ambos métodos requerirían una carga viral mayor de 1.000 copias/ml para disponer de suficientes virus sobre los que realizar dichos estudios. En la actualidad existen consensos tanto nacionales como internaciones que regulan la utilización de estos test en la práctica clínica ${ }^{70-72}$ (Tabla V).

\begin{tabular}{|c|c|}
\hline \multicolumn{2}{|c|}{ INDICACIONES PARA LA REALIZACIÓN DE TEST DE RESISTENCIA } \\
\hline $\begin{array}{c}\text { SIN TRATAMIENTO } \\
\text { ANTIRRETROVIRAL PREVIO }\end{array}$ & $\begin{array}{c}\text { CON TRATAMIENTO } \\
\text { ANTIRRETROVIRAL PREVIO }\end{array}$ \\
\hline \multirow[t]{2}{*}{$\begin{array}{l}\text { Infección aguda por VIH si } \\
\text { se inicia tratamiento (R) }\end{array}$} & $\begin{array}{l}\text { Tras } 1^{\text {er fracaso del }} \\
\text { tratamiento }(C)\end{array}$ \\
\hline & $\begin{array}{l}\text { Tras } 2^{\circ} 03^{\text {er fracaso }} \\
\text { del tratamiento }(R)\end{array}$ \\
\hline Embarazadas ( $\mathrm{R})$ & $\begin{array}{l}\text { Fracasos sucesivos: } \\
\text { 30 o más: }\left(C^{*}\right)\end{array}$ \\
\hline Profilaxis tras exposición (C) & Embarazadas ( $R$ ) \\
\hline \multicolumn{2}{|c|}{$\begin{array}{l}\text { Considerar: }(C) \text {; Recomendado: }(\mathrm{R}) \text {; }\left({ }^{*}\right) \text { De entrada no indicado. } \\
\text { Se están realizando tests de resistencias para decidir la } \\
\text { alternativa terapéutica más favorable en pacientes } \\
\text { multirresistentes. VIH: virus de la inmunodeficiencia humana. }\end{array}$} \\
\hline
\end{tabular}




\section{LAS RESISTENCIAS NO SON LA ÚNICA CAUSA DE FRACASO TERAPÉUTICO}

Cuando se detecta el fracaso de una pauta terapéutica (caída de CD4, ascenso de la carga viral, empeoramiento clínico, etc.) conviene evaluar sus posibles causas: un mal cumplimiento, la absorción insuficiente de fármaco, la presencia de interacciones farmacocinéticas, una escasa potencia de la combinación antiviral y/o la aparición de un nuevo perfil de resistencias.

Uno de los condicionantes que se están estudiando es el referente a las concentraciones plasmáticas de antivirales. Una deficiente absorción (frecuente en estos pacientes), un rápido metabolismo hepático, o un sinfín de interacciones pueden condicionar que -a lo largo de determinados periodos de tiempo- se alcancen concentraciones subterapéuticas. Cada día cobra más interés la monitorización de niveles farmacológicos, aunque es una realidad alejada de la práctica diaria. Parámetros como el área bajo curva (AUC), la concentración máxima $\left(\mathrm{C}_{\max }\right)$ o mínima $\left(\mathrm{C}_{\text {min }}\right)$ y la vida media $\left(\mathrm{T}_{1 / 2}\right)$ se valoran cada día más en la práctica. Otra estrategia utilizada es la asociación de "potenciadores farmacocinéticos" al tratamiento base. Tal es el caso de ritonavir, potente inhibidor de citocromo P450 hepático. Su uso concomitante junto a otro/s inhibidores de proteasa facilita que se mantengan concentraciones séricas más elevadas y durante más tiempo. Incluso, en la actualidad se está estudiando la administración cada 24 horas de componentes de esta familia que originariamente se administraban cada 8 horas $^{47}$.

Pero sin duda el gran problema sin resolver es el del cumplimiento o adherencia terapéutica. Al contrario que otro tipo de tratamientos, se precisa un cumplimiento de -al menos- el $95 \%$ para poder mantener su efectividad; un peor cumplimiento se asocia con el fracaso terapéutico ${ }^{73-75}$. Según estudios al respecto, hasta un tercio de los pacientes olvidan alguna dosis cada 3 días $^{76}$. El tratamiento continuado, la administración de tres tomas al día, el gran número de comprimidos y los efectos adversos son condicionantes importantes.

Dado que el inicio del tratamiento frente al VIH no es urgente en la mayoría de los casos, se considera de la mayor importancia la labor de información, educación y mentalización previa tanto del paciente como de su entorno. Asimismo, habrá que estar expectante en la detección de conductas que favorezcan el mal cumplimiento como, por ejemplo, el abuso de drogas o alcohol, los problemas psiquiátricos, etc. En todo ello el papel próximo del médico de familia puede ser decisivo.

La elección entre las distintas opciones terapéuticas debe hacerse en función de las características del paciente, valorando su forma de vida y profesión. Los esfuerzos en la investigación están locali- zándose en la ampliación de los intervalos entre dosis (buscando la administración única diaria) y en la reducción del número de comprimidos al día. En la actualidad existen dos presentaciones comerciales que, incluso, combinan varios antirretrovirales en la misma pastilla lo que reduce marcadamente la incomodidad del tratamiento ${ }^{77}$.

Sabiendo de la importancia que el cumplimiento meticuloso tiene en la efectividad del tratamiento a largo plazo, en la aparición de resistencias y en la reserva de antirretrovirales, se plantean múltiples estrategias de control y apoyo ${ }^{78-81}$. Se ha valorado la utilidad de la información administrada por el farmacéutico, la vigilancia mediante cuestionarios y control de comprimidos, las visitas periódicas frecuentes, la utilización de avisos y alarmas, etc. Se considera de gran importancia que el paciente disponga de una línea telefónica directa o pueda recurrir a personal especializado de atención inmediata para resolver los problemas que puedan surgir ${ }^{82}$. Últimamente se postula también la posibilidad de realizar terapias directamente observadas sobre personas cuyas características hagan sospechar un cumplimiento incorrecto ${ }^{83-86}$. En definitiva, la labor de educación, seguimiento y apoyo próximo del paciente en tratamiento por personal especializado y con tiempo disponible se presenta como un bastión fundamental para conseguir un correcto cumplimiento de los tratamientos. La simplificación en la posología de los mismos será -asimismo- uno de los objetivos a mejorar por la industria farmacéutica.

Por último, la facilidad de acceso a la medicación por parte del enfermo es otro aspecto que podría ser reconsiderado, especialmente en zonas rurales o en las grandes ciudades. En estas situaciones, el desplazamiento del paciente hasta su hospital de referencia sólo para recoger la medicación podría representar una gran incomodidad y un motivo más de cumplimiento incorrecto.

\section{EL CONTROL DE LA HEPATITIS C: EL NUEVO RETO}

Dado que España ha presentado desde el principio de la pandemia un perfil de transmisión del VIH predominantemente secundario al uso de drogas endovenosas, la coinfección por el virus de la hepatitis C (VHC) es relativamente frecuente. En un centro de ETS de la comunidad de Madrid, el $47 \%$ de los 1.222 usuarios de drogas inyectadas estaban infectados por el VIH. De estos, el 95\% portaban también el $\mathrm{VHC}^{87}$.

Tras el control inmunitario con el TARGA fueron desapareciendo las infecciones oportunistas y mejoró la calidad de vida y la supervivencia. Fue entonces cuando se comenzó a observar una mayor virulencia del virus $C$ en estos pacientes, con más 
rápida evolución hacia cirrosis y hepatocarcinoma en un $20 \%$ de ellos. Mediante biopsia hepática se ha observado que un amplio porcentaje de virus eran del serotipo 1, el menos sensible al tratamiento.

En los últimos años se ha evaluado la biterapia frente al virus $C^{88}$ mediante ribavirina e interferón durante 6-12 meses con resultados más o menos prometedores ${ }^{89-91}$. En breve dispondremos de dos nuevos interferones pegilados, de administración semanal y que alcanzan excelentes niveles séricos ${ }^{92,93}$. El tiempo nos dirá hasta qué punto es efectiva la terapia. Mientras tanto se plantea la necesidad de realizar tratamiento frente al virus $C$ en pacientes coinfectados con buen estado general e inmunitario, e hipertransaminasemia, incluso antes de comenzar el TARGA indefinido frente al VIH.

\section{ALGO SOBRE INTERACCIONES}

Si estamos planteando la necesidad de una terapia combinada frente a una infección, donde las defensas apenas ayudan, donde no podemos -por tanto- permitirnos que caigan las concentraciones séricas y -en algunos casos- necesitamos acercarnos a límites tóxicos de algunos medicamentos, cualquier causa que modifique este equilibrio inestable puede alterar los resultados. Además muchos pacientes precisan tratamientos concomitantes, especialmente frente a la tuberculosis o de mantenimiento con metadona, etc., que pueden interferir con el TARGA y añadir toxicidad.

Partiendo de esta situación, cualquier sustancia que pueda competir en su absorción, con la efectividad de un enzima involucrada en su metabolización, modificar la unión a proteínas plasmáticas, etc., puede hacer que el TARGA sea insuficiente o tóxico. Pero no sólo medicamentos, también determinados productos de uso común como el zumo de pomelo o la hierba de San Juan (Hypericum perfo ratum) pueden alterar el metabolismo del TARGA. Ésta es la razón por la que se recomiende no utilizar productos de herboristería.

Entre los medicamentos, la principal interacción se produce entre aquéllos que modifican la función del citocromo P450. Así, en algunos casos se recomienda usar rifabutina en vez de rifampicina y a que es menos inductor de citocromo P450 e incluso hay que ajustar dosis. El uso concomitante de metadona con efavirenz (inductor del citocromo p450) o nevirapina puede provocar síndrome de abstinencia al inducir su metabolismo precoz ${ }^{94,95}$. Una situación similar ocurre con el uso de claritromicina, de algunas benzodiacepinas, antifúngicos, contraceptivos hormonales, etc. También es importante citar aquí el hecho de que la absorción de algunos medicamentos se ve afectada por las comidas o por el ayuno y que los antiácidos de acción local también pueden alterar dicho proceso. Por último, todos los especialistas han de conocer qué antirretrovirales compiten entre sí por las mismas dianas enzimáticas para no administrarlos conjuntamente ya que su acción no sería aditiva pero sí crecería la importancia de efectos adversos. Tal es el caso de la zidovudina y la estavudina que compiten por la timidinquinasa para su fosoforilación.

Todos estos datos y muchos más son consultados a diario por los especialistas en diversas tablas. De entre ellas, merece la pena mencionar el apoyo vía internet que ofrece Medscape, con frecuentes actualizaciones en este y otros campos y con guías de acceso rápido, comparación de pautas y prevención de efectos adversos (http://hiv.medscape.com/Medscape/HIV/DrugInteractions/index.cfm). Las guías de tratamiento anteriormente citadas ofrecen asimismo información completa sobre las interacciones ${ }^{22-26}$. No obstante, al igual que en otros aspectos, los datos disponibles en diversas combinaciones y con gran número de fármacos son muy limitados, al igual que la experiencia.

\section{EFECTOS ADVERSOS DEL TARGA}

La necesidad de conseguir una aprobación acelerada de antirretrovirales para el control del VIH ha justificado la realización de ensayos clínicos precomercialización de muy corta duración. Por ello, a lo largo de los años posteriores han ido apareciendo nuevas facetas de los fármacos y las combinaciones que no habían sido sospechadas previamente. Recientemente hemos conocido nuevos datos de la toxicidad mitocondrial ${ }^{96}$, seguimos buscando el origen y la solución a la lipodistrofia, y aún siguen surgiendo problemas como la osteoporosis y la necrosis avascular de cadera.

Los análogos de nucleósidos pueden inhibir la polimerasa gamma del ADN mitocondrial. Ello podría dar lugar a miopatía (especialmente debida a zidovudina), neuropatía (zidovudina, didanosina y zalzitabina), pancreatitis (didanosina), esteatosis hepática y acidosis láctica (didanosina, estavudina y zidovudina). Las complicaciones remitirían al suspender el tratamiento (a excepción de la neuropatía periférica y la acidosis tubular renal que pueden perdurar varias semanas tras la retirada $)^{97}$.

La acidosis láctica y la esteatosis grave que aparecen con el uso de análogos de nucleósidos son muy infrecuentes, pero altamente letales ${ }^{98-101}$. Son más frecuentes en mujeres obesas, con tratamientos prolongados ${ }^{26}$. Puede presentarse en forma de síntomas gastrointestinales inespecíficos, debilidad y/o disnea, todo ello de inicio injustificado. La medición del ácido láctico podría ayudar al diagnóstico, pero es difícil de realizar y de resultados inexactos. También el anión gap $\left(\mathrm{Na}-\left[\mathrm{Cl}+\mathrm{CO}_{2}\right]\right)$ 
aparecerá elevado (>16). Las transaminasas, la CPK, la lipasa, amilasa y LDH estarán elevadas. Las pruebas de imagen mostrarían un hígado graso aumentado de tamaño. Esta situación exige la inmediata retirada de los posibles medicamentos causales o de todo el tratamiento y una vigilancia muy estrecha de la evolución (Tabla VI). Recientemente se ha desaconsejado el uso de estavudina y didanosina durante el embarazo después de haberse detectado algunos casos de acidosis láctica en mujeres embarazadas en el último año ${ }^{96}$.

Diversos antirretrovirales pueden inducir exan tema cutáneo, en especial los no análogos de nucleósidos (nevirapina, efavirenz), abacavir y amprenavir. Suele aparecer durante las semanas iniciales del tratamiento y a veces se acompaña de fiebre. Es de tipo maculopapular, eritematoso, confluente y pruriginoso, de predominio en cuerpo y brazos. Más de la mitad de los casos se solucionan espontáneamente sin necesidad de retirar el tratamiento ${ }^{97}$. Aunque es raro, si se complican (afectación de mucosas, fiebre elevada, afectación hepática, etc.) habría que retirar la medicación. En la práctica se utilizan los corticoides y antihistamínicos para paliar estos síntomas. El síndrome de Steven Johnson sólo se ha descrito con nevirapina: ésta es la razón de que el inicio del tratamiento con este fármaco se haga mediante dosis progresivas.

\section{Tabla VI}

SOBRE LOS AJUSTES DEL TARGA

Las dosis de los antirretrovirales se establecen en función de múltiples parámetros farmacocinéticos farmacodinámicos, toxicológicos, etc. A veces no coinciden con las dosis estándar que aparecen en los prospectos ya que han sido ajustadas a medida. Su modificación sin causa puede conllevar la aparición de resistencias o toxicidad.

Cuando se identifica toxicidad debida a un fármaco puede ser sustituido ese medicamento únicamente. Cuando se aprecia un fallo en la eficacia del TARGA y no se dispone de test de resistencias han de sustituirse todos los antirretrovirales simultáneamente.

Los tests genotípicos pueden detectar resistencias a un antirretroviral en concreto dentro de una combinación utilizada. En ese caso, es posible sustituir sólo ese medicamento si se considera oportuno.

Existen múltiples estrategias terapéuticas de potenciación - intensificación de TARGA, de rescate 0 de simplificación, muchas de ellas dentro del contexto de ensayos clínicos.

Si por cualquier razón se precisa la suspensión inmediata del TARGA sin consultar con el especialista, ésta debe realizarse simultáneamente para todos los antirretrovirales.

TARGA: tratamiento antirretroviral del gran actividad
Las reacciones de hipersensibilidad con abacavir, aunque infrecuentes (2-5\%) exigen la retirada inmediata del fármaco y pueden reproducirse e incluso ser mortales si se volviera a utilizar.

No hace más de dos años que se describió la $l i$ podistrofia. Hoy no se sabe la causa realmente. Tampoco existe seguridad de que refleje una única o múltiples alteraciones. En un principio se culpó de ello a los inhibidores de proteasa ${ }^{102-105}$, pero se ha observado también en pacientes que no habían recibido estos fármacos ${ }^{106-109}$ e incluso en pacientes sin tratamiento ${ }^{110}$. Dentro de este gran síndrome se han encuadrado alteraciones morfológicas, del metabolismo lipídico y de la homeostasis de la glucosa.

Morfológicamente se muestra con la aparición de joroba de búfalo y barriga prominente que contrastan con la pérdida de tejido subcutáneo en cara y extremidades. La frecuencia descrita en las anormalidades de distribución grasa varía ampliamente entre las series publicadas ${ }^{111}$. Lo refieren entre el $2 \%{ }^{112}$ y el $84 \% \%^{97,104,105}$. Entre un 15 y un $60 \%$ de los pacientes presentan dislipemia ${ }^{111}$. Las cifras de triglicéridos superan en ocasiones los $1.000 \mathrm{mg} / \mathrm{dl}$ con riesgo de producir pancreatitis, el HDL está importantemente disminuido y tanto el colesterol total como el LDL aumentados. Pese a ello, los escasos datos disponibles no muestran apenas aumento en el número de complicaciones cardiovasculares agudas ${ }^{113,114}$, aunque se precisan más datos a largo plazo e incluyendo más pacientes. Cerca de la mitad de los sujetos en tratamiento con inhibidores de la proteasa ha presentado alguna alteración en el metabolismo glucídico, aunque sólo un 3-5\% tiene hiperglucemia y un $1 \%$ evidencia clínica de diabetes ${ }^{111}$. Ante esta situación es prioritario el identificar y modificar -si se puede- hábitos de riesgo cardiovascular (desarrollar HTA o sobrepeso, o ser asiduo al uso de tabaco, alcohol, etc.). Está indicada la realización de bioquímicas sanguíneas en ayunas cada 3-4 meses (cada 1-2 meses si se observan elevaciones importantes). Se recomienda asociar tratamiento específico con cifras de triglicéridos entre 750 y $1.000 \mathrm{mg} / \mathrm{dl}$ o de LDL entre 130 y 160 $\mathrm{mg} / \mathrm{dl}$. El manejo farmacológico de estos pacientes es delicado dadas las interacciones de importancia entre los medicamentos que utilizan la vía del citocromo P450. Por ello, entre las estatinas, la pravastatina es la más indicada y la atorvastatina puede utilizarse con cuidado. Los fibratos se utilizan para controlar los triglicéridos. No es infrecuente incluso la asociación de gemfibrocilo y atorvastatina en casos especialmente severos ${ }^{115}$. También han sido publicados estudios que sugieren cambiar la terapia antirretroviral ${ }^{116-118}$. Teniendo en cuenta que ritonavir y lopinavir parecen ser los que más alteran el perfil lipídico, su sustitución podría mejorar dichas elevaciones $^{119}$. El ejercicio y la dieta son aspectos a tener en cuenta para el control de estas alteracio- 
nes. Se han utilizado dosis bajas de metformina para el control de la hiperglucemia y -en casos concretos-sulfonilureas, pasando a insulina si es necesario $^{25}$. Para la atrofia facial se están realizando implantes estéticos en zona maxilar superior con éxito relativo. Otras sustancias -en estudio- que se utilizan para tratar de controlar el problema de la lipodistrofia serían los esteroides y la hormona de crecimiento.

Los síndromes lipodistróficos son uno de los principales problemas en el cumplimiento terapéutico ya que el efecto psicológico de la redistribución grasa es elevado. Tal vez se haya asociado precipitadamente su aparición a algún tipo exclusivo de fármacos. Pero ¿hasta qué punto es inducida por los inhibidores de proteasa y por qué unos lo hacen más intensamente que otros? Tras observar que algunos análogos de nucleósidos como la estavudina también facilitan la aparición de lipodistrofia, ¿hasta qué punto los fármacos que actúan sobre la trascriptasa inversa tienen algo que ver en este síndrome? Y, por último, ¿puede estar producido -en parte- por la evolución de la propia enfermedad? Los estudios a largo plazo posiblemente ofrezcan respuestas más sólidas de estas y otras preguntas, nos ayuden a comprender mejor la situación y a poder atajarla. De momento, habrá que conseguir el mejor rendimiento de los antivirales disponibles con el menor índice de efectos adversos y el mejor cumplimiento posible.

Existen otros problemas colaterales bien conocidos más particulares de cada fármaco ${ }^{97}$. Así con el uso de efavirenz se produce sensación de inestabilidad, sueños vividos, somnolencia, insomnio, etc. Se resuelven en las primeras 2-4 semanas pero son molestos para los pacientes y justifican la preferencia de administrarlo por la noche. Indinavir es poco soluble en agua y precipita a modo de cristales en el sistema urinario durante su excreción. Ello provoca cólicos nefríticos más o menos frecuentes $^{120}$. Por esta razón se indica a los pacientes que beban abundante líquido, entre 1 y 5 litros al día, incluso más si ingieren alcohol o hace calor. La diarrea que induce nelfinavir aparece en cerca de un $20 \%$ de los pacientes ${ }^{121}$. Puede ser controlada con dieta, loperamida u otros fármacos astringentes y raramente precisa de la retirada del medicamento. Dado que la metadona produce estreñimiento, el uso de nelfinavir en estos pacientes es de especial interés. Recientemente ha comenzado a utilizarse en ensayos clínicos un nuevo antirretroviral, el primero de la familia de los inhibidores de la fusión, el T-20. Su administración es subcutánea cada 12 horas. Tras la inyección aparece un nódulo que se reabsorverá paulatinamente y puede producir dolor. Aunque la tolerancia va aumentando con su uso y los estudios iniciales sugieren una buena aceptación de los pacientes a este fármaco, habrá que ver sus resultados a lo largo del tiempo. Las guías de tratamiento van recogiendo y actualizando los afectos adversos y se convierten así en documentos imprescindibles para el clínico que siga a estos pacientes.

\section{TENDENCIAS DE FUTURO}

Una realidad clínica actual son las interrupciones estructuradas de tratamiento. Estos procedimientos consisten en suspender la terapia TARGA durante periodos de tiempo comprendidos entre varias semanas y meses, bajo un estricto control analítico ${ }^{122-124}$. Cuando la carga viral y los recuentos de CD4 se acercan a valores comprometidos se reinicia el tratamiento. Estas interrupciones pueden hacerse esporádicamente o intermitentemente. Hasta el momento se han realizado bajo tres planteamientos teóricos diferentes: como forma de reducir la toxicidad del tratamiento TARGA en pacientes de larga evolución e importantes efectos adversos a los antirretrovirales, como estímulo inmunológico ya que -al aumentar la antigenemia- podría favorecerse la reacción inmunitaria, o bien como forma de revertir los virus hacia una forma original sin mutaciones antes de comenzar con una nueva combinación. Fuera del contexto de un ensayo clínico o de una intensa vigilancia médica y analítica, estas prácticas podrían representar un elevado riesgo de progresión clínica de la enfermedad por VIH si se produce una rápida caída de los linfocitos CD4.

También se especula con la posibilidad de influir sobre la respuesta inmune como forma de apoyo a la terapia TARGA. Así se han utilizado estimuladores de la activación de linfocitos como IL-2 $2^{125,126}$ con la finalidad de "despertar" aquellos linfocitos portadores de infección latente para que el TARGA pudiera actuar a ese nivel. También se están utilizando inmunodepresores como el micofenolato mofetilo ${ }^{127,128}$ para controlar la lisis linfocitaria. En cualquier caso, la modulación inmunitaria se muestra como otro aspecto prioritario en la investigación. Así se plantea también hasta qué punto el virus matiza la funcionalidad del timo en el adulto $^{129-133}$ y si se puede actuar a ese nivel, si se podría modificar el factor de adherencia de las células dendríticas, etc.

El controvertido tema de las vacunas frente al VIH todavía se encuentra en una fase precoz. La grandísima diversidad de los virus y su rápida mutagenicidad hacen difícil alcanzar una vacuna eficaz. En la actualidad se están investigando tanto vacunas preventivas como terapéuticas ${ }^{134,135}$. Las primeras buscarían la estimulación de las defensas para hacerlas capaces de rechazar a los virus en una persona sana. El objetivo de las denominadas 
vacunas terapéuticas sería sensibilizar la respuesta defensiva frente a determinados antígenos virales en personas ya infectadas con la intención de modular la propia respuesta inmunitaria.

Y, por supuesto, la industria farmacéutica sigue investigando nuevos antirretrovirales que mejoren a los presentes en todos sus aspectos e incluso que traten de erradicar al virus. La guerra de las patentes y los genéricos podría reducir los recursos invertidos en investigación y desarrollo en este campo.

\section{CONCLUSIÓN}

Tras 20 años de epidemia existen millones de afectados en países en vías de desarrollo. En los países industrializados disponemos de la terapia antirretroviral de gran actividad: muy cara, compleja, que no erradica el virus pero sí mejora la supervivencia y la calidad de vida. Antes de plantearse conseguir la administración libre de esta medicación en el tercer mundo, habría que volcar los esfuerzos en desarrollar una mínima infraestructura diagnóstica, preventiva y clínica para el manejo de dichas terapias.

En nuestro entorno no debemos olvidar al paciente. De su información y mentalización dependerá el correcto cumplimiento de la terapia y con ello se mejorará su efectividad a largo plazo.

Como en otros muchos campos, la labor del médico de Atención Primaria en el diagnóstico precoz, en el seguimiento próximo del paciente y su entorno, en el control epidemiológico y en al apoyo sincronizado a la labor de los especialistas puede ser fundamental.

Tal vez no esté muy lejano el día en que el VIH sea considerado como una enfermedad crónica más de las que se estudian y tratan fuera de los núcleos hospitalarios.

La Fundación para la Formación e Información so bre Tratamientos en el ámbito del VIH (FIT) es una aso ciación sin ánimo de lucro (ONG) cuyo objetivo primor dial es acercar a todas las personas interesadas (afectados, familiares, ONG, etc.) y a profesionales sa nitarios (médicos, ATS, psicólogos clínicos, auxiliares, cuidadores, etc.) las novedades más relevantes que van surgiendo en el ámbito del diagnóstico, tratamiento y seguimiento de los individuos con VIH/SIDA.

\section{AGRADECIMIENTO}

Queremos agradecer a la Dra. Da. Pura Álvarez de la Puente (Roche Farma) su meticuloso apoyo en la búsqueda de los originales más recónditos.

\section{CORRESPONDENCIA:}

Francisco Ledesma Martín-Pintado

Valle de Tobalina 15. Urb Las Lomas

28669 Boadilla de Monte

Madrid

e-mail: fledesma@iponet.es

\section{Bibliografía}

1. Pneumocystis pneumonia-Los Angeles. MMWR Morb Mortal Wkly Rep 1981; 30: 250-2.

2. Barre-Sinoussi F, Chermann JC, Rey F, Nugeyre MT, Chamaret S, Gruest J, et al. Isolation of a T-lymphotropic retrovirus from a patient at risk for acquired immune deficiency syndrom (AIDS). Science 1983; 220: 868-71.

3. Classification system for human T-lymphotropic virus type III/lymphadenopathy-associated virus infections. MMRW Morb Mortal Wkly Rep 1986; 35: 334-9.

4. 1993 Revised classification system for HIV infection and expanded surveillance case definition for AIDS among adolescents and adults. MMRW Morb Mortal Wkly Rep 1992; 41 (RR-17): 1-19.

5. Fischl MA, Richman DD, Grieco MH, Gottlieb MS, Volberding PA, Laskin OL, et al. The efficacy of azidothymidine (AZT) in the treatment of patients with AIDS and AIDS-related complex. A double-blind, placebo-controlled trial. N Engl J Med 1987; 317:185-91.

6. Delta Coordinating Commitee. Delta: a randomised double-blind controlled trial compared combination of zidovu- dine plus didanosine or zalcitabine with zidovudine alone in HIV infected individuals. Lancet 1996; 348: 283-91.

7. HIV Trialists' Collaborative Group. Zidovudine, didanosine, and zalcitabine in the treatment of HIV infection: Meta-analyses of the randomised evidence. Lancet 1999; 353: 2014-25.

8. Hammer S, Squires K, Hughes MD, Grimes JM, Demeter LM, Currier JS, et al. A controlled trial of two nucleoside analogues plus indinavir in persons with human immunodeficiency virus infection and CD4 cell counts of 200 per cubic millimeter or less. N Engl J Med 1997; 337: 725-33.

9. Hammer SM, Katzenstein DA, Hughes MD, Gundacker H, Schooley RT, Haubrich RH, et al. A trial comparing nucleoside monotherapy with combination therapy in HIV infected adults with CD4 cell counts from 200 to 500 per cubic millimeter. ACTG 175. N Engl J Med 1996; 335: 1081-90.

10. Cameron DW, Heath-Chiozzi M, Danner S, Cohen C, Kravcik S, Maurath C, et al. Randomised placebo-controlled trial of ritonavir in advanced HIV-1 disease. The Advanced HIV Disease Ritonavir Study Group. Lancet 1998; 351: 543-9. 
11. Mouton Y, Alfandari S, Valette M, Cartier F, Dellamonica P, Humbert G, et al. Impact of protease inhibitors on AIDSdefining events and hospitalizations in 10 French AIDS reference centers. AIDS 1997; 11: F101-F5.

12. Gulick R, Mellors J, Havlir D, Eron JJ, González C, McMahon D, et al. Treatment with indinavir, zidovudine, and lamivudine in adults with human immunodeficiency virus infection and prior antiretroviral therapy. $\mathrm{N}$ Engl $\mathbf{J}$ Med 1997; 337: 734-9.

13. Torres RA, Barr M. Impact of combination therapy for HIV infection on inpatient census. N Engl J Med 1997; 336: 1531-2.

14. Revicki DA, Swartz C, Wu AW, Haubrich R, Collier AC. Quality of life outcomes of saquinavir, zalcitabine and combination saquinavir plus zalcitabine therapy for adults with advanced HIV infection with CD4 counts between 50 and 300 cells $/ \mathrm{mm}^{3}$. Antivir Ther 1999; 4(1): 35-44.

15. Palella FJ, Delaney KM, Moorman AC, Loveless MO, Fuhrer J, Satten GA, et al. Declining morbidity and mortality among patients with advanced human immunodeficiency virus infection. HIV Outpatient Study Investigators. N Engl J Med 1998; 338: 853-60.

16. Mocroft A, Katlama C, Johnson MA, Pradier C, Antunes F, Mulcahy F, et al. AIDS across Europe, 1994-98: the EuroSIDA study. Lancet 2000; 356: 291-6.

17. Mocroft A, Vella S, Benfield TL, Chiesi A, Miller V, Gargalianos $\mathrm{P}$, et al. Changing patterns of mortality across Europe in patients infected with HIV-1. EuroSIDA Study Group. Lancet 1998; 352: 1752-30.

18. Paul S, Gilbert HM, Ziecheck W, Jacobs J, Sepkowitz KA. The impact of potent antiretroviral therapy on the characteristics of hospitalized patients with HIV infection. AIDS 1999; 13: 415-8.

19. Vittinghoff E, Scheer S, O'Malley P, Colfax G, Holmberg SD, Buchbinder SP. Combination antiretroviral therapy and recent declines in AIDS incidence and mortality. $\mathbf{J}$ Infect Dis 1999; 179: 717-20.

20. Alberdi JC, López-Gay D, Farreras A, Nieto E. Descenso brusco de la mortalidad por VIH/SIDA en la Comunidad de Madrid. Med Clin (Barc) 1998; 110: 679.

21. Iribarren JA, Ramos JT, Guerra L, Coll O, de José MI, Domingo P, et al. Prevención de la transmisión vertical y tratamiento antirretroviral de la infección por el virus de la inmunodeficiencia humana en la mujer embarazada. Enferm Infecc Microbiol Clin 2001; 19: 314-35.

22. Delfraissy JF et groupe des experts "Prise en charge thérapeutique des personnes infectées par le Vih". Prise en charge thérapeutique des personnes infectées par le VIH mise à jour 2000. HIV Med 2000; 1(3): 133-6. http://www.sante.gouv.fr/htm/actu/rap_delf/index_delfra00.htm.

23. Carpenter CCJ, Cooper DA, Fischl MA, Gatell JM, Gazzard BG, Hammer SM, et al. Antiretroviral therapy in adults. Updated recommendations of the AIDS Society-USA panel. JAMA 2000; 283: 381-91. http://www.jama.com.

24. Miró JM, Antela A, Arrizabalaga J, Clotet B, Gatell JM, Guerra L, et al. Recomendaciones GESIDA/Plan Nacional sobre el Sida respecto del tratamiento antirretrovírico en pacientes adultos infectados por el virus de la inmunodeficiencia humana en el año 2000 (I). Enferm Infecc Microbiol Clin 2000; 18 (7): 329-51. http://www.gesidaseimc.com/

25. British HIV Association (BHIVA) guidelines for the treatment of HIV-infected adults with antirretroviral therapy. Julio 2001. http://www.bhiva.org/

26. DHHS, NIH, J Kaiser Family Foundation. Guidelines for the Use of Antirretroviral Agents in HIV-Infected Adults and Adolescents. Febrero 2002. http://www.hivatis.org.
27. ONUSIDA, OMS. Resumen Mundial de la epidemia de VIH/sida. Diciembre 2001. http://www.Unaids.org

28. Secretaría del Plan Nacional Sobre el sida, Registros Autonómicos de casos de sida, Centro Nacional de Epidemiología. Vigilancia epidemiológica de casos de sida en España. Registro Nacional de casos de sida. Balance de la epidemia a 30 de junio de 2001. Informe semestral $n^{\circ} 1$, año 2001. Boletín Epidemiológico Semanal 2001; 9 (17): 181-92.

29. López De Munain J, Cámara MM, Santamaría JM, Zubero Z, Baraia-Etxaburu J, Muñoz J. Características clinicoepidemiológicas de los nuevos diagnósticos de infección por el virus de la inmunodeficiencia humana. Med Clin (Barc) 2001; 117: 654-6.

30. Del Romero J, Castilla J, García S, Clavo P, Ballesteros J, Rodríguez C. Time to trend in incidence of HIV seroconversion among homosexual men repeatedly tested in Madrid, 1998-2000. AIDS 2001; 15(10): 1319-21.

31. Heyden JHA, Catchpole MA, Paget WJ, and the European Study Group. Trends in gonorrhoea in nine western European countries, 1991-96. Sex Transm Infect 2001; 76: 110-06.

32. Doherty L, Fenton K, O'Flanagan D, Couturier E. Evidence for increased transmission of syphilis among homosexual men and heterosexual men and women in Europe. Eurosurveillance Weekly 2000; 4: 001214. http://www.eurosurv.org/2000/001214.htm.

33. Hughes G, Paine T, Thomas D. Surveillance of sexually transmitted infections in England and Wales. Eurosurveillance 2001; 6: 71-80.

34. European Centre for the Epidemiological Monitoring of AIDS. HIV/AIDS Surveillance in Europe. End-Year report 2000. 2001; 64.

35. Dupin N, Jdid R, N'Guyen YT, Gorin I, Franck N, Escande JP. Syphilis and gonorrhoea in Paris: the return. AIDS 2001; 15(6): 814-5.

36. Mellors JW, Rinaldo CR, Gupta P, White RM, Todd JA, Kingsley LA. Prognosis in HIV-1 infection predicted by the quantity of virus in plasma. Science 1996; 272: 116770 .

37. Mellors JW, Muñoz A, Giorgi JV, Margolick JB, Tassoni CJ, Gupta P, et al. Plasma viral load and CD4+ lymphocytes as prognostic markers of HIV-1 infection. Ann Intern Med 1997; 126: 946-54.

38. Kinloch de Loes S, Hirschel BJ, Hoen B, Cooper DA, Tindall B, Carr A, et al. A controlled trial of zidovudine in primary human immunodeficiency virus infection. $\mathrm{N}$ Engl $\mathrm{J}$ Med 1995; 333: 408-13.

39. Hoen B, Dumon B, Harzic M, Venet A, Dubeaux B, Lascoux $\mathrm{C}$, et al. Highly active antiretroviral treatment initiated early in the course of symptomatic primary HIV-1 infection: results of the ANRS 053 trial. J Infect Dis 1999; 180: 1342-6.

40. Zhang L, Ramratnam B, Tenner-Racz K, He Y, Vesanen M, Lewin S, et al. Quantying residual HIV-1 replication in patients receiving combination antiretroviral therapy. $\mathrm{N}$ Eng J Med 1999; 340: 1605-13.

41. Markowitz M, Vesanen M, Tenner-Racz K, Cao Y, Binley JM, Talal A, et al. The effect of commencing combination antiretroviral therapy soon after human immunodeficiency virus type- 1 infection on viral replication and antiviral immune responses. J Infect Dis 1999; 179: 527-37.

42. Montaner JSG, Hogg RS, Yip B, Wood E, Chan K, Craib $\mathrm{KJP}$, et al. Diminished effectiveness of antiretroviral therapy among patients initiating therapy with CD4+ T cell counts below 200/ $\mathrm{mm}^{3}$. 13th International AIDS Conference 2000. Durban, South Africa. Abstract LbPeB7050.

43. Kaplan J, Hanson DL, Karon J. Early initiation of combination antiretroviral therapy (ART): Does it affect clinical outcome? 13th International AIDS Conference 2000. Durban, South Africa. Abstract LbPeB7051. 
44. Kemper CA, Wit MD, Keiser PH, Dube MP, Forthal DN, Leibowitz M, et al. Sequencing of protease inhibitor therapy: insights from an analysis of HIV phenotypic resistance in patients failing protease inhibitors. AIDS 2001; 15: 609-15.

45. Saag MS, Tebas P, Sension M, Conant M, Myers R, Chapman SK, and Viracept Collaborative Study Group. Randomized, double-blind comparison of two nelfinavir doses plus nucleosides in HIV-infected patients (Auguron study 511). AIDS 2001; 15: 1971-8.

46. Hall CS, Raines CP, Barnett SH, Moore RD, Gallant JE. Efficacy of salvage therapy containing ritonavir and saquinavir after failure of single protease inhibitor-containing regimens, AIDS 1999; 13: 1207-12.

47. Van Heeswijk RP, Veldkamp AI, Mulder JW, Meenhorst PL, Lange JM, Beijnen, et al. Once-daily dosing of saquinavir and low-dose ritonavir in HIV-1-infected individuals: a pharmacokinetic pilot study. AIDS 2000; 14: F103-F10.

48. Hirsch M, Steigbigel R, Staszewski S, Mellors J, Scerpella E, Hirschel B, et al. A randomized, controlled trial of indinavir, zidovudine, and lamivudine in adults with advanced human immunodeficiency virus type 1 infection and prior antiretroviral therapy. J Infect Dis 1999; 180: 659-65.

49. Haas DW, Arathoon E, Thompson MA, de Jesus Pedro R, Gallant JE, Uip DE, et al. Comparative studies of two-timesdaily versus three-times-daily indinavir in combination with zidovudine and lamivudine. AIDS 2000; 14: 1973-8.

50. AVANTI 2. Radomized, double-blind trial to evaluate the efficacy and safety of zidovudine plus lamivudine versus zidovudine plus lamivudine plus indinavir in HIV-infected antiretroviral-naive patients. AIDS 2000; 14: 367-74.

51. Gisolf EH, Enting RH, Jurriaans S, de Wolf F, van der Ende ME, Hoetelmans RM, et al. Cerebrospinal fluid HIV1 RNA during treatment with ritonavir/saquinavir or ritonavir/saquinavir/stavudine. AIDS 2000; 14: 1583-9.

52. Collier AC, Coombs RW, Schoenfeld DA, Bassett RL, Timpone J, Baruch A, et al. Treatment of human immunodeficiency virus infection with saquinavir, zidovudine, and zalcitabine. AIDS Clinical Trials Group. N Engl J Med 1996; 334: 1011-7

53. Mathez D, Bagnarelli P, Gorin I, Katlama C, Pialoux G, Saimot G, et al. Reductions in viral load and increases in T lymphocyte numbers in treatment-naive patients with advanced HIV-1 infection treated with ritonavir, zidovudine and zalcitabine triple therapy. Antiviral Ther 1997; 2: 175-83.

54. Starr SE, Fletcher CV, Spector SA, Yong FH, Fenton T, Brundage RC, et al. Combination therapy with efavirenz, nelfinavir, and nucleoside reverse-transcriptase inhibitors in children infected with human immunodeficiency virus type 1. Pediatric AIDS Clinical Trials Group 382 Team. N Engl J Med 1999; 341: 1874-81.

55. Wiznia A, Stanley K, Krogstad P, Johnson G and the PACTG 377 Team. Combination nucleoside analogs plus nelfinavir, nevirapine, or ritonavir in stable antiretroviral therapy-experienced HIV-infected children. 7th Conference on Retroviruses and Opportunistic Infections 2000. San Francisco, EEUU. Abstract 697.

56. D'Aquila RT, Hughes MD, Johnson VA, Fischl MA, Sommadossi JP, Liou SH, et al. Nevirapine, zidovudine and didanosine compared with zidovudine and didanosine in patients with HIV-1 infection. A randomised, double-blind, placebocontrolled trial. Ann Intern Med 1996; 124: 1019-30.

57. Montaner JS, Reiss P, Cooper D, Vella S, Harris M, Conway $\mathrm{B}$, et al. A randomized, double-blind trial comparing combinations of nevirapine, didanosine, and zidovudine for HIV-infected patients: The INCAS Trial. Italy, The Netherlands, Canada and Australia Study. JAMA 1998; 279: 930-7.
58. Staszewski S, Morales-Ramírez J, Tashima KT, Rachlis A, Skiest D, Stanford J, et al. Efavirenz plus zidovudine and lamivudine, efavirenz plus indinavir, and indinavir plus zidovudine and lamivudine in the treatment of HIV-1 infection in adults. N Engl J Med 1999; 341: 1865-73.

59. Friedl AC, Ledergerber B, Flepp M, Hirschel B, Telenti A, Furrer H, et al. Response to first protease inhibitor-and efavirenz- containing antiretroviral combination therapy. The swiss HIV Cohort Study. AIDS 2001; 15: 1793-800.

60. Staszewski S, Keiser P, Gathe J, Haas D, Montaner J, Johnson $\mathrm{M}$, et al. Comparison of antiviral response with abacavir/combivir to indinavir/combivir in therapy-naive adults at 48 weeks (CNA3005). 39th Interscience Conference on Antimicrobial Agents and Chemotherapy 1999. San Francisco, EEUU. Abstract 505.

61. Staszewski S, Keiser P, Montaner J, Raffi F, Gathe J, Brotas $\mathrm{V}$, et al. Abacavir-Lamivudine-Zidovudine vs Indinavir-Lamivudine-Zidovudine in Antiretroviral-Naive HIVInfected Adults: A Randomized Equivalence Trial. JAMA 2001; 285: 1155-63.

62. Soriano V, Miró JM, Guerrero A. Primary resistance to antiretroviral agents. Enferm Infecc Microbiol Clin. 2001; 19(Monográfico): 22-5.

63. Briones C, Pérez-Olmeda M, Rodríguez C, del Romero J, Hertogs K, Soriano V. Primary Genotypic and Phenotypic HIV-1 Drug Resistanse in Recent Seroconverters in Madrid. JAIDS 2001; 26: 145-50.

64. Gallego O, Ruiz L, Vallejo A. Changes in the rate of genotypic resistance to antiretroviral drugs in Spain. AIDS. 2001; 15(14): 1894-6.

65. Montaner JS, Harrigan PR, Jahnke N, Raboud J, Castillo E, Hogg RS, et al. Multiple drug rescue therapy for HIVinfected individuals with prior virologic failure to multiple regimens. AIDS 2001; 15: 61-9.

66. Durant J, Clevenbergh P, Halfon P, Delgiudice P, Porsin S, Simonet $\mathrm{P}$, et al. Drug-resistance genotyping in HIV-1 therapy: the VIRADAPT randomised controlled trial. Lancet. 1999; 353: 2195-9.

67. Baxter JD, Mayers DL, Wentworth DN, Neaton JD, Merigan TC and The CPCRA 046 Study Team. Pilot study of the short-term effects of antirretroviral management based on plasma genotypic antiretroviral resistance testing (GART) in patients failing antiretroviral therapy. 6th Conference on Retroviruses and Opportunistic Infections 1999. Chicago, EEUU. Abstract LB-8.

68. Cohen C, Hunt S, Sension M, Farthing M, Conantes S, Jacobson J, et al. Phenotipic resistance testing significantly improves response to therapy. 7th Conference on Retroviruses and Opportunistic Infections 2000. San Francisco, EEUU. Abstract 237.

69. Flexner C. HIV Genotype and Phenotype-Arresting Resistance? JAMA 2000; 283(18): 2442-4.

70. Soriano V, Ledesma E, and The Spanish Group Resistance Panel. Second Spanish Consensus on the use of Drug Resistance Testing in Clinical Practice. AIDS Rev 2000; 2: 111-8.

71. Hirsch MS, Brun-Vezinet F, D'Aquila RT, Hammer SM, Johnson VA, Kuritzkes DR, et al. Antiretroviral Drug Resistance Testing in Adult HIV-1 Infection: Recommendations of an International AIDS Society-USA Panel. JAMA 2000; 283 (18): 2417-2426.

72. Gatell JM, Blanco JL, Alcami J, Antela A, Arrizabalaga J, Casado JL, et al. Documento de consenso GESIDA sobre la utilización de los estudios de resistencias en la práctica clínica. Enferm Infecc Microbiol Clin. 2001 Feb;19 (Monográfico): 53-60.

73. Paterson DL, Swindells S, Mohr J, Brester M, Vergis EN, Squier C, et al. Adherence to protease inhibitor therapy and outcomes in patients with HIV infection. Ann Intern Med, 2000; 133: 21-30. 
74. Arnsten J, Demas P, Gourevitch M, Bouno D, Farzadegan $\mathrm{H}$, Schoenbaum E. Adherence and viral load in HIV-infected drug users: Comparison of self-report and medication events monitors. 7th Conference on Retroviruses and Opportunistic Infections 2000. San Francisco, EEUU. Abstract 69.

75. Deeks SG, Wrin T, Liegler T, Hoh R, Hayden M, Barbour $\mathrm{JD}$, et al, Virologic and immunologic consequences of discontinuing combination antiretroviral-drug therapy in HIV-infected patients with detectable viremia. N Engl J Med 2001; 344: 472-80.

76. Ickovics JR, Meisler AW. Adherence in AIDS clinical trials: A framework for clinical research and clinical care. J Clin Epidemiol 1997; 50: 385-91.

77. Stone VE, Hogan JW, Schuman P, Rompalo AM, Howard AA, Korkontzelou C, et al. Antiretroviral Regimen Complexity, Self-Reported Adherence, and HIV Patients' Understanding of their Regimens: Survey of Women in the HER Study. JAIDS 2001; 28(2): 124-31.

78. Luber AD, Sherman M, Gotterer H, Shaker-Irwin L, Stryker R. Community collaborations between physicians and pharmacists improved adherence with HIV Consensus Panel Guidelines and enhances the care of HIV infected individuals. 40th Interscience Conference on Antimicrobial Agents and Chemotherapy 2000. Toronto, Canada. Abstract 800.

79. Bangsberg DR, Hecht FM, Clague H, Charlebois D, Ciccarone D, Chesney M, et al. Provider estimate and structured patient report of adherence compared with unannounced pill count. 7th Conference on Retroviruses and Opportunistic Infections 2000. San Francisco, EEUU. Abstract 70.

80. McPherson-Baker S, Malow RM, Penedo F, Jones DL, Schneiderman N, Klimas NG. Enhancing adherence to combination antiretroviral therapy in non-adherent HIVpositive men. AIDS Care 2000; 12: 399-404.

81. Knobel H, Carmona A, Grau S, Saballs P, Gimeno JL, López Colomes JL, et al. Strategies to optimize adherence to highly active antiretroviral treatment. 12th International AIDS Conference 1998. Geneva, Switzerland, Abstract 32322.

82. Grupo de Estudio del Sida de la SEIMC, Sociedad española de Farmacia Hospitalaria, Secretaría Nacional del Plan Nacional sobre el Sida. Recomendaciones para mejorar la adherencia al tratamiento antirretroviral. Ministerio de Sanidad y Consumo 1999.

83. Flanigan T. Forum for Collaborative HIV Research. Directly observed therapy. Adherence to HIV therapy: Building a bridge to success. Washington, D.C. 1999: 2122. http://www.gwu.edu/ chsrp/.

84. Rappaport E. Forum for Collaborative HIV Research. Correctional Institutions. Adherence to HIV therapy: Building a bridge to success. Washington, D.C. 1999: 31-32. http://www.gwu.edu/ chsrp/.

85. Fischl M, Rodríguez A, Scerpella E, Monroig R, Thompson L, Rechtine D. Impact of directly observed therapy on outcomes in HIV clinical trials. 7th Conference on Retroviruses and Opportunistic Infections 2000. San Francisco, EEUU. Abstract 71.

86. Stenzel MS, McKenzie M, Adelson-Mitty J, Flanigan T. Modified directly observed therapy to enhance highly active therapy: 12 month follow-up. 13th International AIDS Conference 2000. Durban, South Africa. Abstract ThPeB4992.

87. Del Romero J, García S, Rodríguez C, Ballesteros J, Clavo $\mathrm{P}$, Gómez R, et al. Prevalencia de coinfección por el virus de la hepatitis $\mathrm{C}$ y el virus de la inmunodeficiencia humana en usuarios de drogas inyectadas y en mujeres que ejercen la prostitución. ETS 2000; 12 (2): 59-63.
88. Kjaergard LS, Krogsgaard K, Gluud C. Interferon alfa with or without ribavirin for chronic hepatitis C: systemic review of randomised trials. BMJ 2001; 323: 11515.

89. Dieterich DT. Sustained virologic response (SVR) following interferon and ribavirin therapy for hepatitis $C$ patients who are co-infected with HIV. 38th Annual Meeting of the IDSA (Infectious Diseases Society of America) 2000. New Orleans, EEUU. Abstract 17.

90. Dieterich D. Weisz K, Goldman D, Talal A, Malicdem L, Markatou M. Interferon -alfa and ribavirin therapy for hepatitis C in HIV co-infected patients. 39th Interscience Conference on Antimicrobial Agents and Chemotherapy 1999. San Francisco, EE.UU. Abstract 429.

91. Landau A, Batisse D, Piketty C, Duong Van Huyen JP, Bloch F, Belec L, et al. Long-term efficacy of combination therapy with interferon- $\alpha 2 b$ and ribavirin for severe chronic hepatitis $\mathrm{C}$ in HIV-infected patients. AIDS 2001; 15: 2149-55.

92. Zeuzem S, Feinman SV, Rasenack J, Heathcote EJ, Lai MY, Gane E, et al. Pegintron Alfa-2a in patients with chronic Hepatitis C. N Engl J Med 2000; 343:1666-72.

93. Heathcote EJ, Shiffman ML, Cooksley WG, Dusheiko GM, Lee SS, Balart L, et al. Pegintron Alfa-2a in patients with chronic hepatitis C and Cirrhosis. N Engl J Med 2000; 343: $1673-80$

94. Baño M D, Agujetas M, López ML, Guillén JL. La nevirapina induce síntomas de abstinencia en pacientes en programa de mantenimiento con metadona con infección por VIH. Rev Clin Esp 2000; 200: 12-4.

95. Clarke S, Mulcahy F, Back D. Managing methadone and non-nucleoside reverse transcriptase inhibitors: guidelines for clinical practice. 7th Conference on Retroviruses and Opportunistic Infections 2000. San Francisco, EEUU. Abstract 88.

96. Bristol-Myers Squibb Company. Healthcare provider important drug warning letter. January 5, 2001.

97. Carr A, Cooper DA. Adverse effects of antiretroviral therapy. Lancet 2000; 356: 1423-30.

98. Kakuda TN. Pharmacology of nucleoside and nucleotide reverse transcriptase inhibitor-induced mitochondrial toxicity. Clin Ther 2000; 22: 685-708.

99. Lonergan JT, Behling C, Pfander H, Hassanein TI, Mathews WC. Hyperlactatemia and hepatic abnormalities in 10 human immunodeficiency virus-infected patients receiving nucleoside analogue combination regimens. Clin Infect Dis 2000; 31: 162-6.

100. Miller KD, Cameron M, Wood LV, Dalakas MC, Kovacs JA. Lactic acidosis and hepatic steatosis associated with use of stavudine: Report of four cases. Ann Intern Med 2000; 133: 192-6.

101. Mokrzycki MH, Harris C, May H, Laut J, Palmisano J. Lactic acidosis associated with stavudine administration: a report of five cases. Clin Infect Dis 2000; 30: 198-200.

102. Miller KD, Jones E, Yanovski JA, Shankar R, Feuerstein I, Falloon J. Visceral abdominal-fat accumulation associated with use of indinavir. Lancet 1998; 351: 871-5.

103. Carr A, Samaras K, Burton S, Law M, Freund J, Chisholm DJ, et al. A syndrome of peripheral lipodystrophy, hyperlipidaemia and insulin resistance in patients receiving HIV prorease inhibitors. AIDS 1998; 12: F51-F8.

104. Carr A, Samaras K, Chisholm DJ, Cooper DA. Pathogenesis of HIV-1-protease inhibitor-associated peripheral lipodystrophy, hyperlipidaemia, and insulin resistance. Lancet 1998; 351: 1881-3.

105. Carr A, Samaras K, Thorisdottir A, Kaufmann GR, Chisholm DJ, Cooper DA. Diagnosis, prediction, and natural course of HIV-1 protease-inhibitor associated lipodystrophy, hyperlipidaemia, and diabetes mellitus: a cohort study. Lancet 1999; 353: 2093-9. 
106. Lo JC, Mulligan K, Tai VW, Algren H, Schambelan M. "Buffalo hump" in men with HIV-1 infection. Lancet 1998; 351: 867-70.

107. Saint-Marc T, Partisani M, Poizot-Martin I, Bruno F, Rouviere O, Lang JM, et al. A syndrome of peripheral fat wasting (lipodystrophy) in patients receiving long-term nucleoside analogue therapy. AIDS 1999; 13: 1659-67.

108. Carr A, Miller J, Law M, Cooper DA. A syndrome of lipoatrophy, lactic acidaemia and liver dysfunction associated with HIV nucleoside analogue therapy: Contribution to protease inhibitor-related lipodystrophy syndrome. AIDS 2000; 14: F25-32

109. Madge S, Kinloch-de-Loes S, Mercey D, Johnson MA, Weller IV. Lipodystrophy in patients naive to HIV protease inhibitors. AIDS 1999; 13: 735-7.

110. Kotler DP, Rosenbaum K, Wang J, Pierson RN. Studies of body composition and fat distribution in HIV-infected and control subjects. J Acquir Immune Defic Syndr Hum Retrovirol 1999; 20: 228-37

111. Shevitz A, Wanke CA, Falutz J, Kotler DP. Clinical perspectives on HIV-associated lipodystrophy syndrome: an update. AIDS 2001; 15: 1917-30.

112. Reus S, Arroyo E, Boix V, Portilla J. Lipodystrophy and hyperglycemia produced by protease inhibitors. Ann Med Interna 2000; 17: 123-6.

113. Coplan P, Nikas A, Saah A, Nessly M, Doll L, Leavitt R, et al. No association observed between indinavir therapy for HIV/AIDS and myocardial infarction in 4 clinical trials with 2825 subjects. 6th International Conference on Retroviruses and Opportunistic Infections 1999. Chicago, EEUU. Abstract 658.

114. Coplan P, Cormier K, Japour A, Maradit-Kremers H, Nikas A, Lewis R, et al. Myocardial infarction incidence in clinical trials of 4 protease inhibitors. 7th Conference on Retroviruses and Opportunistic Infections 2000. San Francisco, EEUU. Abstract 34

115. Henry K, Melroe H, Huebesch J, Hermundson J, Simpson J. Atorvastatin and gemfibrozil for protease-inhibitor-related lipid abnormalities. Lancet 1998; 52: 1031-2.

116. Martínez E, Conget I, Lozano L, Casamitjana R, Gatell JM. Reversion of metabolic abnormalities after switching from HIV-1 protease inhibitors to nevirapine. AIDS 1999; 13: $805-10$

117. Martínez E, García-Viejo MA, Blanco JL, Bianchi L, Buira E, Conget I, et al. Impact of Switching from Human Immunodeficiency Virus Type 1 Protease Inhibitors to Efavirenz in Successfully Treated Adults with Lipodystrophy. Clin Infect Dis 2000; 31: 1266-73.

118. Barreiro P, Soriano V, Blanco F, Casimiro C, de la Cruz JJ, González-Lahoz J. Risks and benefits of replacing protease inhibitors by nevirapine in HIV-infected subjects under long-term successful triple combination therapy. AIDS 2000; 14: 807-12.

119. Wensing AM, Reedijk M, Richter C, Boucher CA, Borleffs JC. Replacing ritonavir by nelfinavir or nelfinavir/saquinavir as part of highly active antiretroviral therapy leads to an improvement of trigliceride levels. AIDS 15; 16: 2191-3.

120. Brodie SB, Keller MJ, Ewenstein BM, Sax PE. Variation in incidence on indinavir-associated nephrolithiasis among HIV-positive patients. AIDS 1998; 12: 2433-8.
121. Markowitz M, Conant M, Hurley A, Schluger R, Duran M, Peterkin $\mathrm{J}$, et al. A preliminary evaluation of nelfinavir mesylate, an inhibitor of human immunodeficiency virus (HIV-1) protease to treat HIV infection. J Infect Dis 1998; 177: 1533-40.

122. García F, Plana M, Ortiz GM, Bonhoeffer S, Soriano A, Vidal C, et al. The virological and immunological consequences of structured treatment interruptions in chronic HIV-1 infection. AIDS 2001; 15(9): 29-40.

123. Ruiz L, Carcelain G, Martínez-Picado J, Frost S, Marfil S, Paredes R, et al. HIV dynamics and T-cell immunity after three structured treatment interruptions in chronic HIV-1 infection. AIDS 2001; 15(9): 19-27.

124. Montaner LJ. Structured treatment interruptions to control HIV-1 and limit drug exposure. Trends in Immunology 2001; 22(2): 92.

125. Smith KA. Low-dose daily interleukin-2 immunotherapy: accelerating immune restoration and expanding HIV-specific T-cell immunity without toxicity. AIDS 2001; 15 (Suppl 2): S28-35.

126. Mitsuyasu RT. The potential role of interleukin-2 in HIV. AIDS 2001; 15 (Suppl 2): S22-27.

127. Coull JJ, Turner D, Melby T, Betts MR, Lanier R, Margolis DM. A pilot study of the use of mycophenolate mofetil as a component of therapy for multidrug-resistant HIV-1 infection. Journal AIDS 2001; 26(5): 423-34.

128. Chapuis AG, Paolo Rizzardi G, D'Agostino C, Attinger A, Knabenhans C, Fleury S, et al. Effects of mycophenolic acid on human immunodeficiency virus infection in vitro and in vivo. Nature Medicine 2001; 6(7): 762-8.

129. Miller ED, Duus KM, Townsend M, Yi Y, Collman R, Reitz M, et al. Human immunodeficiency virus type 1 IIIB selected for replication in vivo exhibits increased envelope glycoproteins in virions without alteration in coreceptor usage: separation of in vivo replication from macrophage tropism. Journal of Virology 2001; 75(18): 8498-506.

130. Boomer JS, Derks RA, Lee GW, DuChateau BK, GilmanSachs A, Beaman KD. Regeneration and tolerance factor is expressed during T-lymphocyte activation and plays a role in apoptosis. Human Immunology 2001; 62(6): 577-88.

131. Lederman MM. Immune restoration and CD4+ T-cell function with antiretroviral therapies. AIDS 2001; 15 (Suppl 2): S11-15.

132. Llano A, Barretina J, Gutierrez A, Blanco J, Cabrera C, Clotet B, et al. Interleukin-7 in plasma correlates with CD4 $\mathrm{T}$-cell depletion and may be associated with emergence of syncytium-inducing variants in human immunodeficiency virus type 1-positive individuals. Journal of Virology 2001; 75(21): 10319-25.

133. Taylor JR, Kimbrell KC, Scoggins R, Delaney M, Wu L, Camerini D. Expression and function of chemokine receptors on human thymocytes: implications for infection by human immunodeficiency virus type 1. Journal of Virology 2001; 75(18): 8752-60.

134. Mitsuyasu RT. AIDS Vaccine 2001: Looking to the Future Medscape HIV/AIDS 7 (5), 2001. http://hiv.medscape.com/Medscape/HIV/journal/2001/v07.n05/mha0927.01 .mits/mig-pnt-mha0927.01.mits.html.

135. Vastag B. HIV Vaccine efforts Inch Forward. JAMA 2001; 286(15): 1826-8. 